\title{
Hair as Forensic Evidence of Explosive Handling
}

\author{
Jimmie C. Oxley, ${ }^{1}$ Ph.D.; James L. Smith, ${ }^{1}$ Ph.D.; \\ Evan Bernier, ${ }^{1}$ B.Sc.; Jesse S. Moran, ${ }^{1}$ B.Sc.; Justin Luongo, ${ }^{1}$ B.Sc.

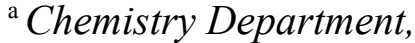 \\ University of Rhode Island, \\ 51 Lower College Road, \\ Kingston, RI 02881
}

\begin{abstract}
:
Hair has the ability to assimilate a variety of chemical compounds. The analysis of hair for determining first-hand exposure to illegal drugs is a popular forensic technique. ${ }^{1-6}$ Molecules such as explosives can also become trapped in hair due to external exposure and detected at trace levels. ${ }^{7-12}$ Hair analysis could prove a powerful, non-invasive method for the detection of individual exposure to illicit explosives. Previous studies showed that in a sealed vessel with adequate headspace, military explosives such as PETN, TNT, and RDX were sorbed to human hair. These organic explosives persisted on hair even after the hair was washed with detergents or solvent. ${ }^{7,8}$ Such sorption was influenced by hair color, and levels of contamination were on the order of micrograms per gram hair after thousands of hours exposure. It was_assumed that in the "real-world" explosives would sorb to hair through the condensation of vapors or by the deposition of solid particulates. This study involved the sampling of hair from students and instructors attending field classes for explosives handling at Fort A.P. Hill, Fredericksburg, VA and Redstone Arsenal, AL. Hair was sampled using combs fitted with cheesecloth, and the cheesecloth was extracted and analyzed by GC-ECD for PETN, TNT, and RDX. On average $80 \%$ of the participants were contaminated with PETN, found in detonating cord, after daily field exercises. Average participant contamination with TNT and RDX in hair ranged from $30 \%$ to $50 \%$.
\end{abstract}




\section{Introduction:}

Hair mirrors its chemical environment. From the early $20^{\text {th }}$ century researchers have tried to quantify chemical exposure in laboratory animals and humans through the analysis of their hair. Research has shown drugs, metals, and other chemicals can accumulate on hair by both internal and external modes. Sampling hair for the detection of drugs is a relatively non-invasive method. ${ }^{1-6}$ The Society for Forensic Toxicology (SOFT) has accepted drug analysis of hair as a confirmatory technique, and the Substance Abuse and Mental Health Administration (SAMHA) has reviewed various factors pertinent to use of this technique as legal evidence. ${ }^{12,13}$ Researchers at the Royal Armament Research and Development Establishment (RARDE) are credited as the first to suggest hair could be used as evidence of exposure to explosives. ${ }^{11}$ They documented the sorption of explosives on cut human hair that had been exposed to EGDN (ethylene glycol dinitrate) and nitrobenzene. Our research group extended their study to include sorption by cut hair of 2,4,6-trinitrotoluene (TNT); hexahydro-1,3,5-trinitro-s-triazine (RDX, the active ingredient in $\mathrm{C} 4)$; pentaerythritol tetranitrate (PETN, the explosive found in detonating cord and sheet explosives); EGDN; triacetone triperoxide (TATP), diacetone diperoxide (DADP), nitroglycerin (NG), and 2,4-dinitrotoluene (DNT). In addition to demonstrating differences in the extent of sorption over time, our studies have shown hair color affected the extent of explosive sorption. As expected, water solubility affected the persistence of explosives upon washing. ${ }^{7-10}$

The purpose of the present study was to determine how laboratory experiments with hair translate into the field by pre- and post-blast hair sampling of individuals involved in explosive disposal. Participants consisted primarily of bomb technicians attending refresher training offered by the Bureau of Alcohol, Tobacco, Firearms and Explosives (ATF) at Fort A.P. Hill in 
Fredericksburg, VA (2003) and a group of Army Corp Engineers investigating the efficiency of blow-in-place protocols at Redstone Arsenal in Alabama (2005). ${ }^{14}$ Although non-military explosives (fireworks and ammonium nitrate formulations) were also used at Fort A.P. Hill, our analyses screened for only the military high explosives; PETN, TNT, and RDX. Three mechanisms of explosives contamination were postulated: (1) condensation of explosive vapor; (2) deposition of airborne explosive particulates; and (3) cross-contamination involving the transport of explosive particulates to hair via hands or clothing (i.e. gloves, hats etc.). Participants in these studies combed their hair using a comb fitted with cheesecloth wet with methanol. The used gauze/comb assembly was wrapped with aluminum foil, placed inside of a plastic bag and returned to the University of Rhode Island (URI) laboratory for subsequent solvent extraction and explosives analysis by GC-ECD. Herein is reported the recovery of PETN, TNT, and RDX from the hair of individuals participating in these tests.

\section{Materials and Methods}

Reagents

Ultra-pure (2-mMho) water was prepared by passing distilled water through a series of mixed bed and activated carbon filtration cartridges (Barnstead International - Dubuque, Iowa). "Water" referred to herein implies the use of this ultra-pure water. Organic solvents used were HPLC grade acetonitrile (Fisher Scientific, UV-cutoff 190nm), HPLC grade methanol (Fisher Scientific, UV-cutoff 205nm), and acetone. Ultra high purity (UHP 99.999\%) helium, nitrogen, and hydrogen were used as carrier/makeup gases for gas chromatography and pre-purified nitrogen (99.9\%) was used for solvent evaporation.

\section{Combs for Sampling}

Black "unbreakable" plastic combs were purchased in bulk and cleaned of residual contaminants by two 15 minute washes in a 1:1 acetone/water bath. Reagent grade cheesecloth 
[Fisher Scientific cheesecloth wipes (cat.\# 06-665-29) $46 \mathrm{~cm}$ X 92cm - 100\% pure reagent cotton] was cut into $13 \mathrm{~cm} \times 9 \mathrm{~cm}$ bilayer pieces and cleaned of impurities by Soxhlet extraction in acetonitrile for a minimum of five full rinses. After drying on aluminum foil, each cheesecloth piece was folded twice widthwise and fed onto the teeth of a clean comb as seen in Figure 1. The combs were then wrapped in aluminum foil in sets of ten, and sealed in Ziploc ${ }^{\circledR}$ bags for transportation to the testing sites.

\section{Sampling Protocol}

Fort A.P. Hill, Fredericksburg,VA: Sampling was conducted during two separate ATF explosives training classes which included October 27-30, 2003 (Week 1) and November 3-6, 2003 (Week 2). Explosives used during both instructor demonstrations and student exercises are listed in Table 1. At the beginning of each week participants were asked to complete a consent form with questions pertaining to their experience with explosives and personal physical characteristics. Hair combings were performed each day before field work commenced and immediately following each day's field work. Directly before sampling, participants rinsed their hands with tap-water and dried them thoroughly with a paper towel. The cheesecloth on each comb was moistened with 1 to $3 \mathrm{~mL}$ of methanol from a polyethylene squeeze bottle. Each participant was asked to comb their hair at least 10 times on each side of a single comb taking care not to touch the cheesecloth directly with their hands. Used combs were individually wrapped in aluminum foil and stored in small Ziploc ${ }^{\circledR}$ bags. Printed labels were affixed to the bags onto which participants were asked to provide their unique assigned identification number, the time of sampling, and any information pertaining to hair treatment on that specific day. The sample bags were separated in batches according to sampling date and time and placed in gallon size Ziploc $\AA^{\circledR}$ bags for storage and transport. Within one week of collection sample bags were stored in a freezer $\left(-24^{\circ} \mathrm{C}\right)$ to prevent possible long term degradation prior to analysis. 
Redstone Arsenal, AL: Sampling was conducted during explosive exercises over the timeframe April 4-28, 2005. The purpose of the exercises was to determine how much explosive contamination would be found in the environment after the firing of certain explosives. ${ }^{14}$ Unlike the AP Hill exercises, explosive handling was generally limited to Arsenal personnel, but most participants were involved in collecting debris after each firing. Explosives used during the Redstone exercises are listed in Table 2. The collection procedure was identical to that used at Fort A.P. Hill except water was used in place of methanol to moisten the cheesecloth fitted on the combs.

\section{Sample Processing}

Information written on the sample bag labels was recorded at the University of Rhode Island (URI) laboratory. Cheesecloth pieces were removed from the combs using clean stainless steel forceps. Each piece of cheesecloth was placed in a clear, labeled, screw-capped vial $(85 \mathrm{~mm}$ $\mathrm{H} \times 23 \mathrm{~mm} \mathrm{OD}$ ) and $\sim 17 \mathrm{~mL}$ of acetonitrile was added. Vials were shaken for one hour mechanically (150 linear oscillations/minute for A.P. Hill samples and 325 orbital oscillations/minute for Redstone samples), removed, shaken vigorously by hand for one minute, and placed back on the mechanical shaker for an additional hour. Extracts were decanted through a glass funnel into a clean, clear screw-capped vial ( $85 \mathrm{~mm} \mathrm{H} \mathrm{x} 23 \mathrm{~mm} \mathrm{OD})$. The cheesecloth was transferred from the vial to the funnel, and residual solvent was pressed out of the cheesecloth using a spatula. The cheesecloth was placed back into the original vial and washed with an additional $7 \mathrm{~mL}$ of acetonitrile by one minute of vigorous hand shaking. The second extract was decanted, pressed from the cheesecloth, and combined with the appropriate primary extract. Vials of filtered extract were capped and stored at $-24^{\circ} \mathrm{C}$ until they could be concentrated using a nitrogen stream. 
AP Hill sample extracts were concentrated to dryness with nitrogen via a custom designed manifold system ( $\sim 1400 \mathrm{~mL} / \mathrm{min}$ per vial) which held up to 22 vials. An additional $1.00 \mathrm{~mL}$ of water was added to Redstone samples prior to nitrogen concentration in order to prevent trace volatilization of TNT. At dryness, $2.00 \mathrm{~mL}$ of acetonitrile was added to each vial, and the vials were resealed and gently agitated ( $\sim 60$ oscillations/minute) on an orbital shaker (Clay Adams - Nutator) for 30 minutes. The final extract was transferred to a labeled $2 \mathrm{~mL}$ amber GC vial (Agilent Technologies) and stored at $-24^{\circ} \mathrm{C}$ until GC-ECD analysis.

\section{Quantitative Analysis}

Fort A.P. Hill Samples: A Gas Chromatograph with a micro Electron Capture Detector (Agilent 6890N GC- $\mu$ ECD) was used to detect and quantify PETN, TNT, and RDX in the comb/ cheesecloth extracts. The column was a fused silica DB5-MS (J\&W Scientific - 30m X 0.25mm ID $\left.\mathrm{X} 0.25 \mu \mathrm{m} d_{f}\right)$. The injection port temperature was set at $175^{\circ} \mathrm{C}(5: 1$ split $)$ with an injection volume of $1 \mu \mathrm{L}$. The carrier gas was helium $(8.0 \mathrm{~mL} / \mathrm{min}$, constant flow $)$ and the makeup gas was nitrogen $\left(40.0 \mathrm{~mL} / \mathrm{min}\right.$.). The oven temperature program was as follows: $50^{\circ} \mathrm{C}$ for $1 \mathrm{~min}$., $20^{\circ} \mathrm{C} / \mathrm{min}$. to $170^{\circ} \mathrm{C}$ with $1 \mathrm{~min}$. hold, $5^{\circ} \mathrm{C} / \mathrm{min}$. to $185^{\circ} \mathrm{C}, 25^{\circ} \mathrm{C} / \mathrm{min}$. to $280^{\circ} \mathrm{C}$ with 5 minute final hold. The detector temperature was $300^{\circ} \mathrm{C}$.

Redstone Samples: A GC-ECD (Hewlett Packard 5890 Series II) was used to quantify the PETN, TNT, and RDX. The column was a fused silica DB1 (J\&W Scientific - 6m X 0.53mm ID $\mathrm{X} 1.5 \mu \mathrm{m} d_{f}$ ). The injection port temperature was set at $175^{\circ} \mathrm{C}$ (splitless) with an injection volume of $1 \mu \mathrm{L}$. The carrier gas was hydrogen $\left(41.5 \mathrm{~mL} / \mathrm{min}\right.$. measured at $\left.27^{\circ} \mathrm{C}\right)$ and the makeup gas was nitrogen $\left(63 \mathrm{~mL} / \mathrm{min}\right.$.). The oven temperature program was as follows: $100^{\circ} \mathrm{C}$ for 2 minutes, $10^{\circ} \mathrm{C} / \mathrm{min}$. to $200^{\circ} \mathrm{C}, 20^{\circ} \mathrm{C} / \mathrm{min}$. to $250^{\circ} \mathrm{C}$ w/ $5 \mathrm{~min}$. final hold. The detector temperature was $300^{\circ} \mathrm{C}$. 
At GC injector temperatures of 200 to $250^{\circ} \mathrm{C}$ the signal response for RDX and TNT was elevated; while that of PETN was much lower due to degradation in the injector. At lower injector temperatures $\left(165^{\circ} \mathrm{C}\right)$ the instrument response for $\mathrm{RDX}$ decreased significantly; therefore, the optimized injector temperature was chosen to be $175^{\circ} \mathrm{C}$. RDX and TNT peak tailing was reduced by keeping the detector temperature at $300^{\circ} \mathrm{C}$ and using a ramp rate of 5 or $10^{\circ} \mathrm{C} / \mathrm{min}$ as TNT and RDX eluted.

To conserve sample extract, $250 \mu \mathrm{L}$ flat bottom glass vial inserts (Agilent Technologies) were utilized during GC analysis. A low temperature re-circulating water bath (Endocal - Neslab Instrument Inc., Newington, $\mathrm{NH}$ ) was used to keep GC vials stored in the auto-sampler trays of both chromatographs at a constant temperature $\left(5-10^{\circ} \mathrm{C}\right)$ during long runs.

\section{Calibration Standards}

Analytical stock solutions of $1000 \mathrm{ppm}$ were individually prepared from PETN, TNT and RDX reference materials dissolved in acetonitrile. Calibration standards containing all three high explosive analytes were prepared from the stock solutions with concentrations ranging from 10 to $0.01 \mathrm{ppm}$ in acetonitrile.

\section{Quality Assurance}

Unused combs returned from the sampling sites were extracted and processed as control samples using the identical extraction procedure as was used on samples. Detection limit studies were accomplished with these control samples. Cleaned cheesecloth was used for performing laboratory spike recovery studies and as preparation blanks included with each sample set. Spiked samples were prepared by adding $0.50 \mathrm{~mL}$ of the $1 \mathrm{ppm}$ PETN/TNT/RDX calibration solution via volumetric pipette onto a piece of folded cheesecloth prior to extraction, yielding a concentration of $250 \mathrm{ppb}$ of each explosive in the final sample extract to be analyzed. For every ten extracted samples analyzed, one spiked sample, one preparation blank, and one control 
sample were generated. Accuracy of calibration standards was verified using a certified EPA explosives standard mix (Cerilliant EPA 8330 - cat. \# ERE-021 containing $200 \mu \mathrm{g} / \mathrm{mL}$ of the following components: 4-amino-2-6-dinitrotoluene, 1,3-dinitrobenzene, 2,6-dinitrotoluene, nitrobenzene, 3-nitrotoluene, 1,3,5-trinitrobenzene, 2-amino-4,6-dinitrotoluene, 2-nitrotoluene, 4-nitrotoluene, 2,4-dinitrotoluene, tetryl, TNT, RDX, and HMX). The concentrated mix was diluted to prepare a $200 \mathrm{ppb}$ laboratory control standard that was analyzed once with every set of samples from Fort A.P. Hill. Redstone sample extracts were analyzed with individually prepared, 1 ppm laboratory control standards for PETN (Cerilliant cat.\# P-037 - 1000ug/mL), TNT (Cerilliant cat.\# ERT-0225 - 1000ug/mL) and RDX (Cerilliant cat.\# ERR-0015 - 1000ug/ $\mathrm{mL})$.

In a small percentage $(\sim 5 \%)$ of the acetonitrile extracts, matrix interferences, probably caused by hair care products and natural oils, were observed as white suspended solids in the concentrated samples. Such interferences contributed to high baseline noise and made it necessary to evaluate the significance of the data. ${ }^{15}$ Limits of quantification (LOQ) and limits of detection (LOD) were established for PETN, TNT and RDX for each sample set. The LOD for any analytical procedure is the point at which detection is feasible. LOD values ( $\mathrm{S} m$ ) were calculated based on the analysis of 20 control samples, using eq. 1 where $\mathbf{S} \boldsymbol{m}=L O D, \mathbf{S}_{\mathbf{b l}}=$ avg. analyte signal, $\boldsymbol{k}=3, \mathbf{s}_{\mathbf{b l}}=$ std. dev. signal.

$$
\mathrm{S} m=\mathrm{S}_{\mathrm{bl}}+k \mathrm{~S}_{\mathrm{bl}}
$$

The LOQ is the concentration at which quantitative results can be reported with a high degree of confidence. LOQ values were calculated based on the same 20 control samples as the product of 10 and $\mathbf{s}_{\text {bl. }}$ Peak values below the LOD were considered non-detectable (ND), while peak values between the LOD and LOQ were considered non-calculable (NC). Due to instability in the ECD 
response, dynamic LOD and LOQ values, recalculated daily for each sample set, were found using eq. 2 and eq.3:

$$
\begin{aligned}
& \mathrm{LOD}=\left[1 / 8\left(a 1_{n} / a 1_{i}+\ldots+a 8_{n} / a 8_{i}\right)\right]\left[\mathrm{LOD}_{i}\right] \\
& \mathrm{LOQ}=\left[1 / 8\left(a 1_{n} / a 1_{i}+\ldots+a 8_{n} / a 8_{i}\right)\right]\left[\mathrm{LOQ}_{i}\right]
\end{aligned}
$$

where

$$
\begin{aligned}
& a(1-8)_{\mathrm{n}}=\text { peak area of new calibration standard (8 standards total) } \\
& a(1-8)_{i}=\text { peak area of original calibration standard (8 standards total) } \\
& \mathrm{LOD}_{i}=\text { initial LOD }(\mathrm{ppm}) \quad \mathrm{LOQ}_{i}=\text { initial LOQ }(\mathrm{ppm}) .
\end{aligned}
$$

Average LOD values for samples containing TNT, PETN, and RDX were usually near 6, 40, and $30 \mathrm{ppb}$, respectively, and average LOQ values were usually about 10, 100, and $70 \mathrm{ppb}$, respectively.

Chromatographic conditions for analysis of the Fort A.P. Hill samples on the 6890 GC$\mu$ ECD fully resolved TNT, PETN, and RDX. Figure 2 is a chromatogram of a 5 ppm mixed calibration standard of TNT (8.3min.), PETN (8.9min.), and RDX (10.1min.). The peak for PETN was poorly shaped due to degradation in the 30 meter DB5-MS column. It was necessary to perform quantification using one of degradation products of PETN, seen in Figure 2 as peaks at $4.3,5.3,6.2$, and 7.4 minutes. Peak ratios of the degradation products were unchanged in samples and standards stored for 3 months at $-24^{\circ} \mathrm{C}$. The peak at 5.3 minutes was chosen for quantification of PETN as it gave a very linear response to changes in PETN concentration and was conveniently positioned away from the majority of baseline sample interference observed in the comb extracts. A shorter (6 meter) megabore (0.53 mm I.D.) column was used for analyses of the Redstone samples on the 5890-ECD. These column dimensions have has been shown to reduce degradation of PETN and other explosives. Figure 3 is a chromatogram of a $0.5 \mathrm{ppm}$ 
mixed calibration standard of TNT (6.4min.), PETN (7.2min.), and RDX (8.1min.) analyzed on the 5890-ECD.

Figure 4 shows the chromatogram of actual extracted sample (9414-1030A, A.P. Hill) containing TNT, PETN, and RDX. Identification of these explosives was contingent on their retention time relative to the retention time of the calibration standards. A sample peak which eluted within \pm 0.005 minutes ( \pm 0.3 seconds) of a calibration standard peak was considered a positive identification. Quantification was accomplished by comparison of peak areas with calibration curves of standards (peak areas versus concentration). Calibration curves were linear $\left(\mathrm{R}^{2} \geq 0.99\right)$ with a linear dynamic range of $0.05-30 \mathrm{ppm}$ and an average relative standard deviation (avg. RSD) of 5.0\% for PETN; $0.01-1$ ppm with avg. RSD of $1.6 \%$ for TNT; and 0.01 2 ppm with avg. RSD of $3.5 \%$ for RDX. Worksheets were established containing raw and processed chromatographic data for each sample set which included: peak retention time, peak area, peak height, recalculated LOD/LOQ values, concentration based on standard calibration curves, explosive mass (ng) recovered, and standard percent recovery for PETN, TNT and RDX. Information from individual comb bag labels and personal consent forms along with masses of any of the explosive analytes were compiled for all samples in a master spreadsheet.

\section{Results and Discussion}

Tables 3 and 4 summarize the data for Week 1 and 2 at Fort A.P. Hill and Table 5 includes the average data from the Redstone Arsenal shots. Average results are reported for the date and time [morning (Mor.) before working with explosives versus afternoon (Aft.) after working with explosives]. Each column is headed by the total number of participants sampled at that time, and results below list the number of participants found containing each of the three explosives and the average amount of each explosive (ng) recovered from the contaminated 
participants. Standard deviations are similar and, in some cases, even greater than the average amounts of explosives found on individual's hair. Thus, although average amounts of explosive contamination are reported in order to give a rough approximation of the amounts of explosive available for detection, the more significant number is the percent of participants who were contaminated.

At A.P.Hill (Week 1 and Week 2), more participants became contaminated with PETN and at greater quantities, than with TNT or RDX. Detonating cord (det cord) was used for most shots and is a ready source of contamination because it is packed with powdered PETN. ${ }^{16}$ Det cord was also used at Redstone Arsenal, although most participants in the hair study were involved in debris collection and not direct setup of the explosive shots. Therefore, explosive contamination at Redstone was not as widespread in terms of participant percentages and the quantity of explosives recovered. For example, on average greater than $80 \%$ of participants at A.P. Hill were contaminated with PETN at over 3000ng while only $24 \%$ of Redstone participants were on average contaminated with 170ng PETN.

Surprisingly, at all three test series, several individuals showed detectable levels of RDX and PETN (A.P. Hill) on Monday morning before any explosives handling commenced. A similar observation was made at DSTL for people involved in handling explosives in the preparation of canine training aids. ${ }^{7,10}$ For the A.P. Hill tests, where the hair of participants was tested every morning, it is easily seen that the number of participants contaminated at the start of the day, before handling explosives, steadily increased during the week. Morning sampling showed overnight persistence of PETN, TNT, and RDX, but the explosives which were present in higher amounts the previous afternoon were more likely to remain overnight. For example, PETN contamination in the hair of all the A.P. Hill participants (mean $=7068 \mathrm{ng}$ ) on the 
afternoon of 11/05 led to the carry-over of PETN contamination for over $60 \%$ of those sampled the next morning. TNT recovered from the same participants on the afternoon of $11 / 05$ was at an average of only $64 \mathrm{ng}$ and was detected on only $4 \%$ of these participants on the following morning (Tables 3 and 4)._. Other factors which would affect persistence are the solubility of the explosive and its mode of binding to hair. At $20^{\circ} \mathrm{C}$, both TNT and RDX have low solubility in $100 \mathrm{~g}$ water ( 0.012 and $0.005 \mathrm{~g}$ respectively) while PETN is considered insoluble. In $100 \mathrm{~g}$ water at $100^{\circ} \mathrm{C}$, TNT and RDX have slightly increased solubility ( 0.147 and $0.28 \mathrm{~g}$ respectively) while PETN is unpublished. ${ }^{17,18}$ By the final afternoon sampling during Week 2 at A.P. Hill every participant was contaminated with PETN and greater than 50\% showed traces of RDX and TNT.

Correlations between the quantity of PETN, TNT, and RDX recovered from individuals' hair and individual physical characteristics were limited by the diversity of the sample pool. Participant hair length was mostly short or missing (bald), and greater than $90 \%$ of the participants were Caucasian males. A comparison of participants' hair color to explosive contamination was examined for the Week 1 and 2 Fort A.P. Hill samples combined. Table 6 shows hair color versus average explosives recovered (ng) and the percent of participants contaminated with PETN, TNT, and RDX. The relative percentages of explosive contamination ( $\sim 90 \%$ PETN, $\sim 50 \%$ RDX, and $\sim 30 \%$ TNT) seem to hold across all hair colors within a deviation near $10 \%$. There was a slight bias towards greater contamination on black hair, but this could be associated with experimental error.

\section{Conclusions}

Trace organic explosives can be successfully recovered from and detected on the hair of exposed individuals. Results from morning samplings, before any explosives were handled, indicate that explosive contamination can persist overnight, especially when the previous afternoon exposure was high. Over $60 \%$ of participants on the last morning of the A.P. Hill 
testing had detectable amounts of PETN in their hair. Additionally, the average amount of PETN recovered in the afternoon_(after explosive handling) increased over the course of each week at A.P. Hill._ There appeared to be no correlation between the presence of hair treatment products and the degree or likelihood of explosive contamination, but these products did lead to increased matrix interferences in the chromatographic analyses. The limited participant pool, mostly Caucasian males with short hair, did not allow correlation of contamination with other physical characteristics, such as hair color or length.

\section{References}

1. R.L. Dupont and W.A. Baumgartner. Drug Testing by Urine and Hair Analysis:

Complimentary Features and Scientific Issues, Forensic Sci Int., 1995, 70(1-3), 63.

2. K.S. Kelly and R. Rogers. Detection of Misreported Drug Use in Forensic Populations: An Overview of Hair Analysis, Bull Am. Acad Psychiatry Law, 1996, 24(1), 85-94.

3. P. Kintz, editor. Drug Testing in Hair. CRC Press: New York, 1996.

4. D.L. Hubbard, Hair as a Matrix for Biomarkers of Pesticide Exposure. Salt Lake City Utah Press, 2001.

5. R.W. Goldblum, L.R. Goldbaum and W.N. Piper, Barbiturate Concentrations in the Skin and Hair of Guinea Pigs. J. Invest. Dem., 1954, 22, 121.

6. R.O. Pehl and M. Parkes, Hair Analysis on Learning and Behaviour Problems. New York: Prager Publications: New York, 1980; 138.

7. J.C. Oxley, J.L. Smith, L.J. Kirschenbaum, K.P. Shinde and S. Marimganti, Accumulation of Explosives in Hair. J Forensic Sci., 2005, 50(4), 826.

8. J.C. Oxley, J.L. Smith, L.J. Kirschenbaum and S. Marimganti, Accumulation of explosives in hair: Part II: Factors Affecting Sorption, J Forensic Sci., 2007, 52(6). 
9. J.C. Oxley, J.L. Smith, L.J. Kirschenbaum, S. Marimganti, S. and S. Vadlamannati, Detection of explosives in hair using ion mobility spectrometry accepted J Forensic Sci., May 2008.

10. M. Marshall, K.P. Sanders, J.C. Oxley, J.L. Smith, and L. Egee, Explosive Recovery from Hair. Science and Justice, 2002, 42(3), 137.

11. D.F. Wardleworth and S.A. Ancient, in The Sorption of Explosives on Human Hair, International Symp. Analysis \& Detection of Explosives, Quantico, VA, 1983; U.S. Depart. Justice, F.B.I.; Quantico, VA, 1983.

12. Society for Forensic Toxicology (SOFT), Consensus statement, 1990, 1992.

13. Substance Abuse and Mental Health Administration of the U.S. Dept. of Health \& Human Services, "Factors Required for Reliable Workplace Drug Testing, Aug. 1998.

14. J.C. Pennington, T.F. Jenkins, G. Ampleman, B. Thiboutot, A.D. Hewitt, B. Brochu, J. Robb, E. Diaz, J. Lewis and H. Colby, Distribution and Fate of Energetics of DoD Test and Training Ranges: Intr Report 6; U.S. Army Corp of Engineers, ERDC TR-06-12; Nov. 2006. 15. Harvey, David. Modern Analytical Chemistry. 1st edition. McGraw-Hill Companies, Inc. Boston, MA 2000, pp 95-96.

16. J.C. Oxley, J.L. Smith, E. Resende, E. Pearce, and Chamberlain, T. Trends in Explosive Contamination, J. Forensic Sci. 2003, 48(2), 1-9.

17. J.C. Oxley, J.L. Smith, J Brady, F. Dubnikova, R. Kosloff, L. Zeiri, Y. Zeiri The Raman and IR fingerprint spectroscopy of peroxide-based explosives submitted J. Phys. Chem. B.

18. Encyclopedia of Explosives and Related Items; Picatinny Arsenal; Dover, NJ; ed. B.T Fedoroff \& O.E. Sheffield, 1966, C-616, vol. 3 (RDX); ed. S.M. Kaye, 1978, P-89, vol 8; (PETN) and 1980, T-260, vol. 9 (TNT). 


\section{List of Tables}

Table 1: Explosives Used at Fort A.P. Hill (2003)

Table 2: Explosives Used at Redstone Arsenal (2005)

Table 3: Hair Contamination at Fort A.P. Hill, Week 1 (2003)

Table 4: Hair Contamination at Fort A.P. Hill, Week 2 (2003)

Table 5: Hair Contamination at Redstone Arsenal (2005)

Table 6: Hair Color vs. Explosive Contamination at Fort A.P. Hill (2003) 
Table 1: Explosives Used at Fort A.P. Hill (2003)

\begin{tabular}{|c|c|c|c|c|}
\hline & $27-$ Oct & 28-Oct & 29-Oct & 30-Oct \\
\hline PETN containing & det cord & $\begin{array}{l}\text { det cord, } \\
\text { pentolite } \\
\text { booster, } \\
\text { detonator }\end{array}$ & $\begin{array}{c}\text { det cord, } \\
\text { pentolite } \\
\text { booster }\end{array}$ & $\begin{array}{l}\text { det cord, } \\
\text { pentolite } \\
\text { booster }\end{array}$ \\
\hline RDX containing & & $\begin{array}{c}\text { oil well } \\
\text { perforators }\end{array}$ & & \\
\hline TNT containing & & $\begin{array}{c}\text { pentolite } \\
\text { booster }\end{array}$ & $\begin{array}{c}\text { pentolite } \\
\text { booster }\end{array}$ & $\begin{array}{c}\text { pentolite } \\
\text { booster }\end{array}$ \\
\hline NG containing & $\begin{array}{l}\text { smokeless } \\
\text { powder }\end{array}$ & $\begin{array}{c}\text { dynamite, } \\
\text { smokeless } \\
\text { powder }\end{array}$ & dynamite & dynamite \\
\hline AN or other & fireworks & & shock tube & $\begin{array}{c}\text { fireworks, } \\
\text { AN emulsion }\end{array}$ \\
\hline & 3-Nov & 4-Nov & 5-Nov & 6-Nov \\
\hline PETN containing & $\begin{array}{c}\text { det cord, } \\
\text { pentolite } \\
\text { booster }\end{array}$ & $\begin{array}{c}\text { det cord, } \\
\text { pentolite } \\
\text { booster }\end{array}$ & det cord & $\begin{array}{c}\text { det cord, } \\
\text { pentolite } \\
\text { booster }\end{array}$ \\
\hline RDX containing & & $\begin{array}{c}\text { oil well } \\
\text { perforators }\end{array}$ & & $\begin{array}{c}\text { oil well } \\
\text { perforators }\end{array}$ \\
\hline TNT containing & $\begin{array}{l}\text { pentolite } \\
\text { booster }\end{array}$ & $\begin{array}{l}\text { pentolite } \\
\text { booster }\end{array}$ & & $\begin{array}{c}\text { pentolite } \\
\text { booster, soil } \\
\text { contaminated w/ } \\
\text { TNT \& DNT }\end{array}$ \\
\hline NG containing & & & dynamite & \\
\hline AN or other & $\begin{array}{c}\text { fireworks, AN } \\
\text { emulsion }\end{array}$ & & & $\begin{array}{c}\text { ANFO, } \\
\text { AN emulsion }\end{array}$ \\
\hline
\end{tabular}


Table 2: Explosives Used at Redstone Arsenal (2005)

\begin{tabular}{|c|c|c|c|c|c|c|c|c|}
\hline & 5-Apr & 8-Apr & 18-Apr & 19-Apr & $20-A p r$ & $25-\mathrm{Apr}$ & $27-A p r$ & 28-Apr \\
\hline PETN containing & det cord & det cord & det cord & det cord & det cord & det cord & det cord & det cord \\
\hline RDX containing & $\begin{array}{l}\text { Haliburton shaped } \\
\text { charge, } 105 \mathrm{~mm} \\
\text { projectile }\end{array}$ & $\begin{array}{l}\text { Haliburton shaped } \\
\text { charge, comp. B, } \\
\text { 105mm projectile }\end{array}$ & 105mm projectile & 105mm projectile & $\begin{array}{l}\text { Haliburton shaped } \\
\text { charge, } 105 \mathrm{~mm} \\
\text { projectile }\end{array}$ & $\begin{array}{c}\mathrm{C} 4,155 \mathrm{~mm} \\
\text { projectile }\end{array}$ & $\begin{array}{l}\text { Haliburton shaped } \\
\text { charge, } 155 \mathrm{~mm} \\
\text { projectile }\end{array}$ & $105 \mathrm{~mm}$ projectile \\
\hline TNT containing & $105 \mathrm{~mm}$ projectile & $\begin{array}{c}\text { comp. B, } 105 \mathrm{~mm} \\
\text { projectile }\end{array}$ & $\begin{array}{c}\text { comp. B, } 105 \mathrm{~mm} \\
\text { projectile }\end{array}$ & $\begin{array}{c}\text { TNT, } 105 \mathrm{~mm} \\
\text { projectile }\end{array}$ & $\begin{array}{c}\text { TNT, comp. B, } \\
105 \mathrm{~mm} \text { projectile }\end{array}$ & $\begin{array}{c}\text { comp. B, } 155 \mathrm{~mm} \\
\text { projectile }\end{array}$ & $155 \mathrm{~mm}$ projectile & $\begin{array}{c}\text { TNT, } 105 \mathrm{~mm} \\
\text { projectile }\end{array}$ \\
\hline AN or other & $\begin{array}{c}\mathrm{HMX}(105 \mathrm{~mm} \\
\text { projectile) }\end{array}$ & $\begin{array}{l}\text { HMX (105mm } \\
\text { projectile) }\end{array}$ & $\begin{array}{c}\text { Kinepak (AN/NM), } \\
\text { HMX (105mm } \\
\text { projectile) }\end{array}$ & $\begin{array}{c}\text { Kinepak (AN/NM), } \\
\text { HMX (105mm } \\
\text { projectile) }\end{array}$ & $\begin{array}{l}\mathrm{HMX}(105 \mathrm{~mm} \\
\text { projectile) }\end{array}$ & $\begin{array}{c}\mathrm{HMX}(155 \mathrm{~mm} \\
\text { projectile) }\end{array}$ & $\begin{array}{l}\mathrm{HMX}(155 \mathrm{~mm} \\
\text { projectile) }\end{array}$ & $\begin{array}{c}\text { Kinepak (AN/NM), } \\
\text { HMX (105mm } \\
\text { projectile) }\end{array}$ \\
\hline
\end{tabular}


Table 3: Hair Contamination at Fort A.P. Hill, Week 1 (2003)

\begin{tabular}{|c|c|c|c|c|c|c|c|c|c|c|}
\hline & \multicolumn{2}{|c|}{$27-$ Oct } & \multicolumn{2}{|c|}{ 28-Oct } & \multicolumn{2}{|c|}{$29-$-Oct } & \multicolumn{2}{|c|}{ 30-Oct } & \multicolumn{2}{|c|}{ Overall Average } \\
\hline & Mor. & Aft. & Mor. & Aft. & Mor. & Aft. & Mor. & Aft. & Morning & Afternoon \\
\hline \# Participants & 29 & 24 & 23 & 20 & 18 & 20 & 20 & 13 & 23 & 19 \\
\hline Part. w/ PETN & 1 & 16 & 6 & 15 & 0 & 18 & 12 & 13 & 5 & 16 \\
\hline$\%$ contaminated & $3 \%$ & $67 \%$ & $26 \%$ & $75 \%$ & $0 \%$ & $90 \%$ & $60 \%$ & $100 \%$ & $21 \%$ & $81 \%$ \\
\hline Avg. PETN (ng) & 341 & 520 & 686 & 1529 & 0 & 4567 & 844 & 5913 & 468 & 3132 \\
\hline StdDev. (ng) & $\mathrm{n} / \mathrm{a}$ & \pm 336 & \pm 945 & \pm 1628 & $\mathrm{n} / \mathrm{a}$ & \pm 4064 & \pm 354 & \pm 5420 & \pm 650 & \pm 2862 \\
\hline Part. w/ TNT & $\overline{0}$ & $\overline{6}$ & $\overline{2}$ & 10 & $\overline{0}$ & $\overline{4}$ & $\overline{0}$ & $\overline{3}$ & $\overline{1}$ & $\overline{6}$ \\
\hline$\%$ contaminated & $0 \%$ & $25 \%$ & $9 \%$ & $50 \%$ & $0 \%$ & $20 \%$ & $0 \%$ & $23 \%$ & $2 \%$ & $30 \%$ \\
\hline Avg. TNT (ng) & 0 & 40 & 99 & 97 & 0 & 84 & 0 & 658 & 25 & 220 \\
\hline StdDev. (ng) & $\mathrm{n} / \mathrm{a}$ & \pm 15 & \pm 80 & \pm 140 & n/a & \pm 33 & $\mathrm{n} / \mathrm{a}$ & \pm 649 & \pm 80 & \pm 209 \\
\hline Part. w/ RDX & 1 & 4 & 1 & 8 & 1 & 4 & 0 & 7 & 1 & 6 \\
\hline$\%$ contaminated & $3 \%$ & $17 \%$ & $4 \%$ & $40 \%$ & $6 \%$ & $20 \%$ & $0 \%$ & $54 \%$ & $3 \%$ & $30 \%$ \\
\hline Avg. RDX (ng) & 96 & 206 & 1283 & 545 & 169 & 361 & 0 & 1065 & 387 & 544 \\
\hline StdDev. (ng) & $\mathrm{n} / \mathrm{a}$ & \pm 86 & $\mathrm{n} / \mathrm{a}$ & \pm 653 & $\mathrm{n} / \mathrm{a}$ & \pm 107 & $\mathrm{n} / \mathrm{a}$ & \pm 1171 & n/a & \pm 504 \\
\hline
\end{tabular}


Table 4: Hair Contamination at Fort A.P. Hill, Week 2 (2003)

\begin{tabular}{|c|c|c|c|c|c|c|c|c|c|c|}
\hline & \multicolumn{2}{|c|}{ 3-Nov } & \multicolumn{2}{|c|}{ 4-Nov } & \multicolumn{2}{|c|}{ 5-Nov } & \multicolumn{2}{|c|}{ 6-Nov } & \multicolumn{2}{|c|}{ Overall Average } \\
\hline & Mor. & Aft. & Mor. & Aft. & Mor. & Aft. & Mor. & Aft. & Morning & Afternoon \\
\hline \# Participants & 25 & 28 & 29 & 30 & 29 & 27 & 27 & 28 & 28 & 28 \\
\hline Part. w/ PETN & 4 & 17 & 3 & 27 & 8 & 26 & 18 & 28 & 8 & 25 \\
\hline$\%$ contaminated & $16 \%$ & $61 \%$ & $10 \%$ & $90 \%$ & $28 \%$ & $96 \%$ & $67 \%$ & $100 \%$ & $30 \%$ & $87 \%$ \\
\hline Avg. PETN (ng) & 493 & 2007 & 283 & 7032 & 387 & 7068 & 730 & 7741 & 473 & 5962 \\
\hline StdDev. (ng) & \pm 187 & \pm 4722 & \pm 125 & \pm 13530 & \pm 137 & \pm 6125 & \pm 438 & \pm 26980 & \pm 222 & \pm 12840 \\
\hline Part. w/ TNT & 0 & 2 & 0 & 7 & 1 & 6 & 1 & 19 & 1 & 9 \\
\hline$\%$ contaminated & $0 \%$ & $7 \%$ & $0 \%$ & $23 \%$ & $3 \%$ & $22 \%$ & $4 \%$ & $68 \%$ & $2 \%$ & $30 \%$ \\
\hline Avg. TNT (ng) & 0 & 88 & 0 & 81 & 21 & 64 & 29 & 145 & 13 & 95 \\
\hline StdDev. (ng) & $\mathrm{n} / \mathrm{a}$ & $\mathrm{n} / \mathrm{a}$ & $\mathrm{n} / \mathrm{a}$ & \pm 68 & $\mathrm{n} / \mathrm{a}$ & \pm 46 & $\mathrm{n} / \mathrm{a}$ & \pm 192 & $\mathrm{n} / \mathrm{a}$ & \pm 102 \\
\hline Part. w/ RDX & 2 & 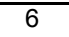 & 0 & 23 & 2 & 15 & 2 & 15 & 2 & 15 \\
\hline$\%$ contaminated & $8 \%$ & $21 \%$ & $0 \%$ & $77 \%$ & $7 \%$ & $56 \%$ & $7 \%$ & $54 \%$ & $5 \%$ & $52 \%$ \\
\hline Avg. RDX (ng) & 263 & 391 & 0 & 3075 & 533 & 334 & 418 & 439 & 304 & 1060 \\
\hline StdDev. (ng) & \pm 26 & \pm 263 & $\mathrm{n} / \mathrm{a}$ & \pm 7052 & \pm 541 & \pm 228 & \pm 262 & \pm 368 & \pm 276 & \pm 1980 \\
\hline
\end{tabular}


Table 5: Hair Contamination at Redstone Arsenal (2005)

\begin{tabular}{|c|c|c|c|c|c|c|c|c|c|c|c|c|c|c|}
\hline & \multirow{2}{*}{$\begin{array}{l}\text { 4-Apr } \\
\text { Mor. }\end{array}$} & \multirow{2}{*}{$\begin{array}{c}\text { 5-Apr } \\
\text { Aft. }\end{array}$} & \multirow{2}{*}{$\begin{array}{l}\text { 6-Apr } \\
\text { Aft. }\end{array}$} & \multirow{2}{*}{$\begin{array}{l}\text { 8-Apr } \\
\text { Aft. }\end{array}$} & \multicolumn{2}{|c|}{ 18-Apr } & \multirow{2}{*}{$\begin{array}{c}\text { 19-Apr } \\
\text { Aft. }\end{array}$} & \multirow{2}{*}{$\begin{array}{c}\text { 20-Apr } \\
\text { Aft. }\end{array}$} & \multicolumn{2}{|c|}{ 25-Apr } & \multirow{2}{*}{$\begin{array}{c}\text { 27-Apr } \\
\text { Aft. }\end{array}$} & \multirow{2}{*}{$\begin{array}{c}\text { 28-Apr } \\
\text { Aft. }\end{array}$} & \multicolumn{2}{|c|}{ Overall Average } \\
\hline & & & & & Mor. & Aft. & & & Mor. & Aft. & & & Morning & Afternoon \\
\hline \# Participants & 10 & 10 & 10 & 10 & 7 & 7 & 8 & 8 & 6 & 7 & & & 8 & 8 \\
\hline Part. w/ PETN & 0 & 2 & 1 & 4 & 0 & 1 & 2 & 4 & 0 & 1 & 1 & 1 & 0 & 2 \\
\hline$\%$ contaminated & $0 \%$ & $20 \%$ & $10 \%$ & $40 \%$ & $0 \%$ & $14 \%$ & $25 \%$ & $\mathbf{5 0} \%$ & $0 \%$ & $14 \%$ & $14 \%$ & $20 \%$ & $0 \%$ & $24 \%$ \\
\hline Avg. PETN (ng) & 0 & 91 & 518 & 224 & 0 & 187 & 151 & 148 & 0 & 216 & 17 & 3 & 0 & 173 \\
\hline StdDev. (ng) & n/a & \pm 68 & $\mathrm{n} / \mathrm{a}$ & \pm 355 & $\mathrm{n} / \mathrm{a}$ & $\mathrm{n} / \mathrm{a}$ & \pm 63 & \pm 107 & $\mathrm{n} / \mathrm{a}$ & $\mathrm{n} / \mathrm{a}$ & $\mathrm{n} / \mathrm{a}$ & n/a & & \\
\hline Part. w/ TNT & 0 & $\overline{0}$ & $\overline{0}$ & 0 & 0 & $\overline{6}$ & $\overline{7}$ & 0 & 0 & 0 & 0 & 0 & 0 & $\overline{1}$ \\
\hline$\%$ contaminated & $0 \%$ & $0 \%$ & $0 \%$ & $0 \%$ & $0 \%$ & $86 \%$ & $88 \%$ & $0 \%$ & $0 \%$ & $0 \%$ & $0 \%$ & $0 \%$ & $0 \%$ & $18 \%$ \\
\hline Avg. TNT (ng) & 0 & 0 & 0 & 0 & 0 & 331 & 248 & 0 & 0 & 0 & 0 & 0 & 0 & 64 \\
\hline StdDev. (ng) & n/a & $\mathrm{n} / \mathrm{a}$ & n/a & $\mathrm{n} / \mathrm{a}$ & $n / a$ & \pm 341 & \pm 326 & $n / a$ & n/a & $\mathrm{n} / \mathrm{a}$ & n/a & $\mathrm{n} / \mathrm{a}$ & & \\
\hline Part. w/ RDX & 2 & 3 & 4 & 5 & 3 & 6 & 8 & 8 & 4 & 5 & 1 & 1 & 3 & 5 \\
\hline$\%$ contaminated & $20 \%$ & $30 \%$ & $40 \%$ & $50 \%$ & $43 \%$ & $86 \%$ & $100 \%$ & $100 \%$ & $67 \%$ & $71 \%$ & $14 \%$ & $20 \%$ & $39 \%$ & $57 \%$ \\
\hline Avg. RDX (ng) & 643 & 94 & 100 & 150 & 36 & 727 & 1201 & 151 & 30 & 78 & 40 & 32 & 236 & 286 \\
\hline StdDev. (ng) & \pm 509 & \pm 64 & \pm 137 & \pm 105 & \pm 44 & \pm 622 & \pm 1193 & \pm 138 & \pm 21 & \pm 128 & $n / a$ & n/a & & \\
\hline
\end{tabular}


Table 6: Hair Color vs. Explosive Contamination at Fort A.P. Hill (2003)

\begin{tabular}{|c|c|c|c|c|c|c|c|}
\hline \multirow{3}{*}{$\begin{array}{l}\text { Mean daily } \\
\text { participants } \\
(\text { total }=50)\end{array}$} & & \multicolumn{6}{|c|}{ Overall Mean } \\
\hline & & \multicolumn{2}{|c|}{ PETN } & \multicolumn{2}{|c|}{ TNT } & \multicolumn{2}{|c|}{ RDX } \\
\hline & & Mor. & Aft. & Mor. & Aft. & Mor. & Aft. \\
\hline \multirow{3}{*}{ Brown (27) } & Part. w/ explosives & 7 & 22 & 1 & 8 & 2 & 11 \\
\hline & $\%$ contaminated & $25 \%$ & $81 \%$ & $2 \%$ & $32 \%$ & $5 \%$ & $42 \%$ \\
\hline & Mean mass (ng) & 511 & 4293 & 22 & 139 & 299 & 743 \\
\hline \multirow{3}{*}{ Black (6) } & Part. w/ explosives & 1 & 6 & 0 & 3 & 1 & 3 \\
\hline & $\%$ contaminated & $14 \%$ & $95 \%$ & $0 \%$ & $45 \%$ & $11 \%$ & $54 \%$ \\
\hline & Mean mass (ng) & 168 & 4426 & 0 & 170 & 56 & 982 \\
\hline \multirow{3}{*}{ Blonde (4) } & Part. w/ explosives & 1 & 3 & 0 & 0 & 0 & 2 \\
\hline & $\%$ contaminated & $19 \%$ & $81 \%$ & $0 \%$ & $13 \%$ & $6 \%$ & $50 \%$ \\
\hline & Mean mass (ng) & 512 & 2405 & 0 & 16 & 75 & 492 \\
\hline \multirow{3}{*}{ Gray (12) } & Part. w/ explosives & 4 & 8 & 1 & 3 & 0 & 4 \\
\hline & $\%$ contaminated & $36 \%$ & $88 \%$ & $4 \%$ & $24 \%$ & $0 \%$ & $43 \%$ \\
\hline & Mean mass (ng) & 420 & 5127 & 9 & 36 & 0 & 410 \\
\hline \multirow{3}{*}{$\operatorname{Red}(1)$} & Part. w/ explosives & 1 & 1 & 0 & 0 & 0 & 1 \\
\hline & $\%$ contaminated & $50 \%$ & $100 \%$ & $0 \%$ & $25 \%$ & $0 \%$ & $75 \%$ \\
\hline & Mean mass (ng) & 237 & 2427 & 0 & 4 & 0 & 620 \\
\hline
\end{tabular}




\section{List of Figures}

Fig .1. Comb fitted with cheesecloth for hair sampling

Fig. 2. Chromatogram of 5ppm calibration standard (PETN/TNT/RDX) from 6890 GC- $\mu E C D$

Fig. 3. Chromatogram of 0.5ppm calibration standard (PETN/TNT/RDX) from 5890 GC-ECD

Fig. 4. Chromatogram of sample 9414-1030A (Fort A.P. Hill) from 6890 GC- $\mu E C D$ 
Fig .1. Comb fitted with cheesecloth for hair sampling

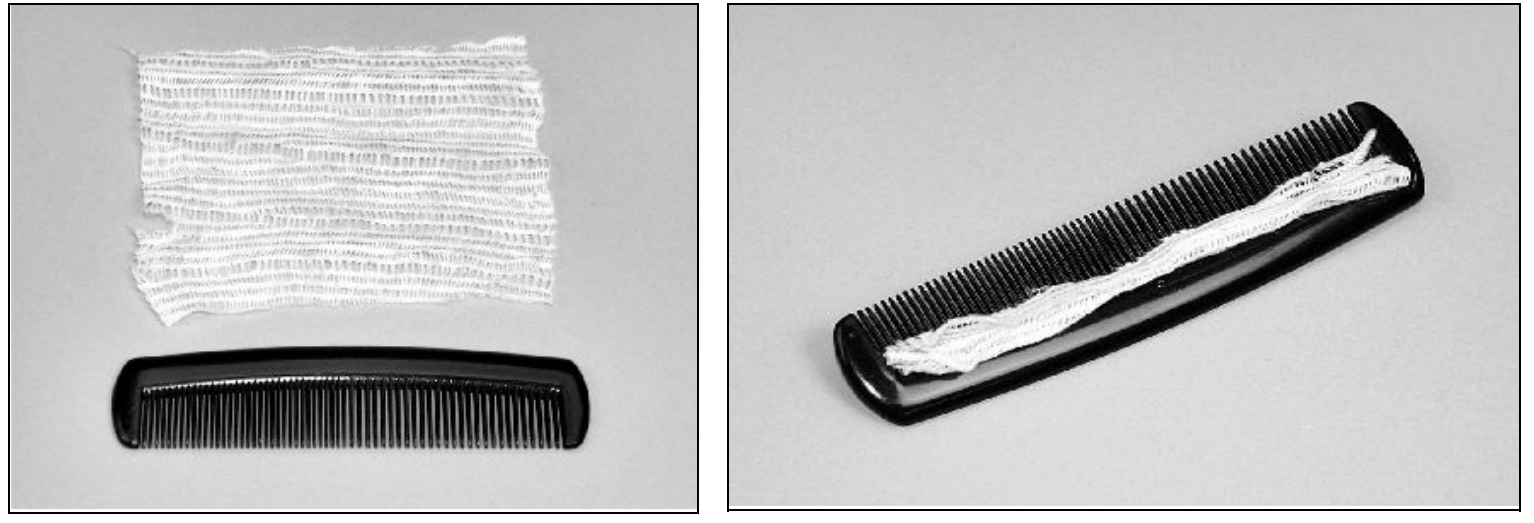


Fig. 2. Chromatogram of 5ppm calibration standard (PETN/TNT/RDX) from $6890 \mathrm{GC}-\mu E C D$

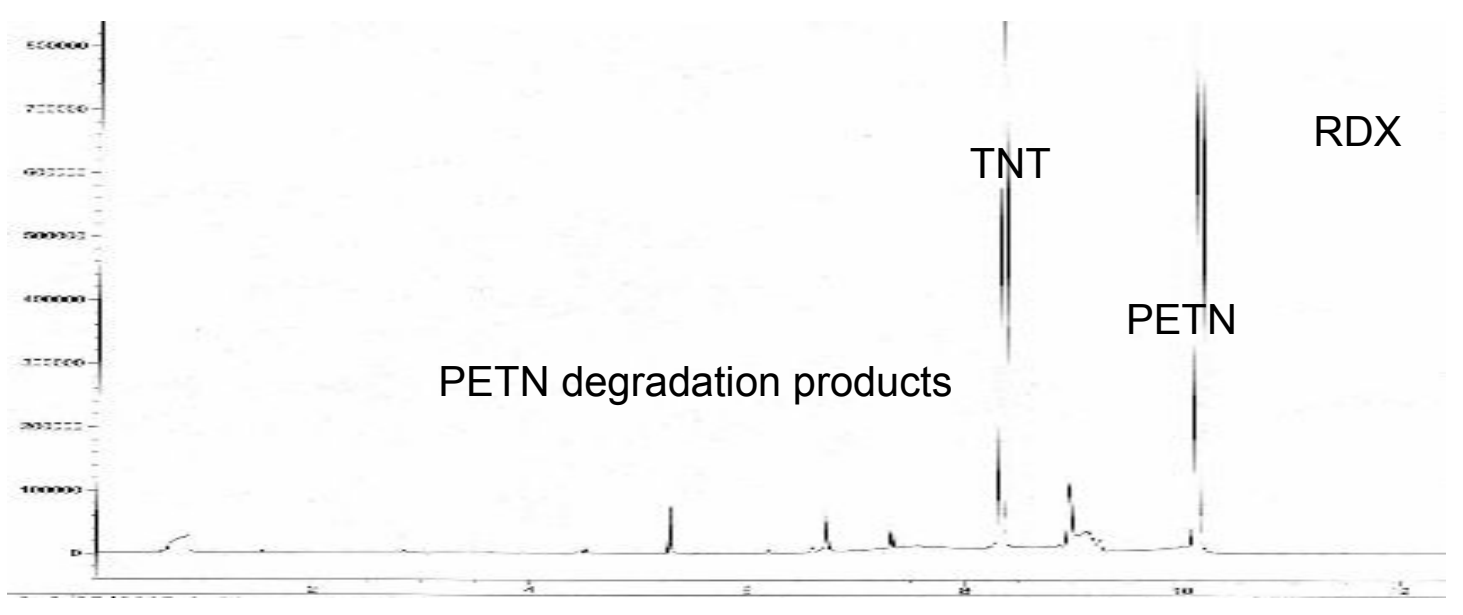


Fig. 3. Chromatogram of 0.5ppm calibration standard (PETN/TNT/RDX) from 5890 GC-ECD

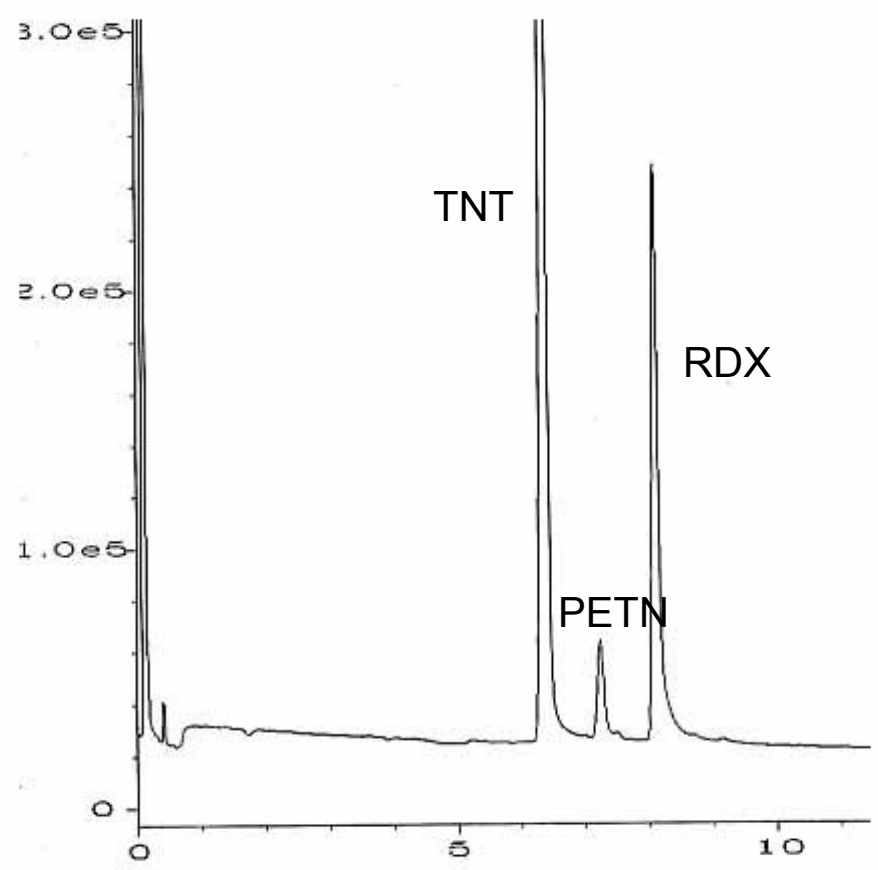


Fig. 4. Chromatogram of sample 9414-1030A (Fort A.P. Hill) from 6890 GC- $\mu E C D$

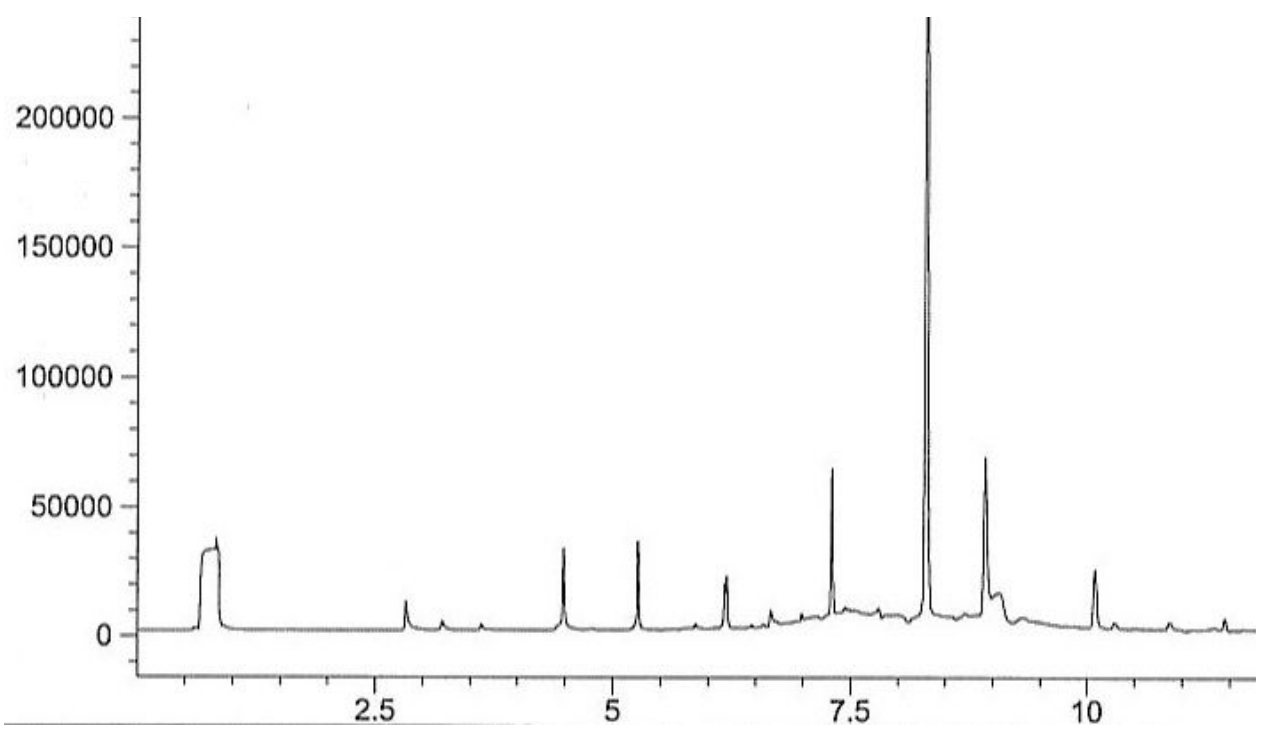

